https://doi.org/10.46344/JBINO.2020.v09i03.19

\title{
A REVIEW ON CURRENT TRENDS OF HIV IN AFRICA; A CASE OF NIGERIA CONTEXT: CHALLENGES AND WAY FORWARD
}

\author{
Abdulkadir B. ', Dazy D.B. ${ }^{2}$, Samira I.G. ${ }^{2}$, Aladelokun J. D. ${ }^{2}$, Nafisat S. T. ${ }^{2}$, Olaosebikan V. O.2, Ibrahim E. ${ }^{2}$, \\ Samira A. ${ }^{2}$, Nwadigwe M. O.2., Abubakar M. A. ${ }^{2}$, and Farida A.T. ${ }^{2}$, \\ ' Department of Microbiology Umaru Musa Yaradua University Katsina \\ 2 Department of Microbiology Kebbi State University of Science and Technology Aliero
}

\begin{abstract}
HIV/AIDS is a significant public health alarm and lead to mortality in numerous region of Africa. Even though the continent is having a population of about $15.2 \%$ of the world's population, more than two-thirds of the infected worldwide - some 35 million people were Africans, of whom 15 million have already died. Nigeria has the second-largest HIV epidemic in the world. Although the rate of HIV prevalence among adults is much less (1.5\%) than other countries within the sub-Saharan African region, the size of Nigeria's population means 1.9 million people were living with HIV in 2018, UNAIDS estimates that around two-thirds of new HIV infections in West and Central Africa occur in Nigeria, certain groups still carry more significant HIV problem when compared with the rest of the population in Nigeria, Sex workers, homosexuals and people who inject drugs make up $3.4 \%$ of the people, hitherto account for around $32 \%$ of new HIV infections. Challenges associated with HIV/AIDS in Nigeria are cultural barriers, legal barriers, funding, HIV testing, and counseling. Way forward to solving the problems HIV prevention program, increased availability of Pre-exposure prophylaxis, HIV education, prevention of mother-to-child transmission. Nigeria is a populous country, and the number recorded for the people living with HIV is high though many interventions were set on apipeline to tackle it burdens and also reduces the chance of onward HIV transmission to others, encouraging HIV testing among the Nigerian population to ensure everyone knows their HIV status is key to any informed strategic plan.
\end{abstract}

Keywords: Challenges, HIV, Sex, and Viral load

No: of Figures: 04

No: of References: 10 


\section{INTRODUCTION}

$\mathrm{HIV}$ is the virus that can result to acquired immunodeficiency syndrome or AIDS if not treated. Contrasting some other viruses, the human body cannot get free of HIV totally, even with its management (UNAIDS 2018).HIV virus that can be transmitted via certain body fluids that can attacks the body's immune system,
(CD4 cells, often called T cells). Over period, HIV can destroy so many of these cells that the body cannot fight off infections and disease. These individual cells help the immune system fight off infections. Opportunistic infections take advantage of a fragile immune system and signal that the person has AIDS. (UNAIDS 2018)

\section{Source: Pepfar 2017}

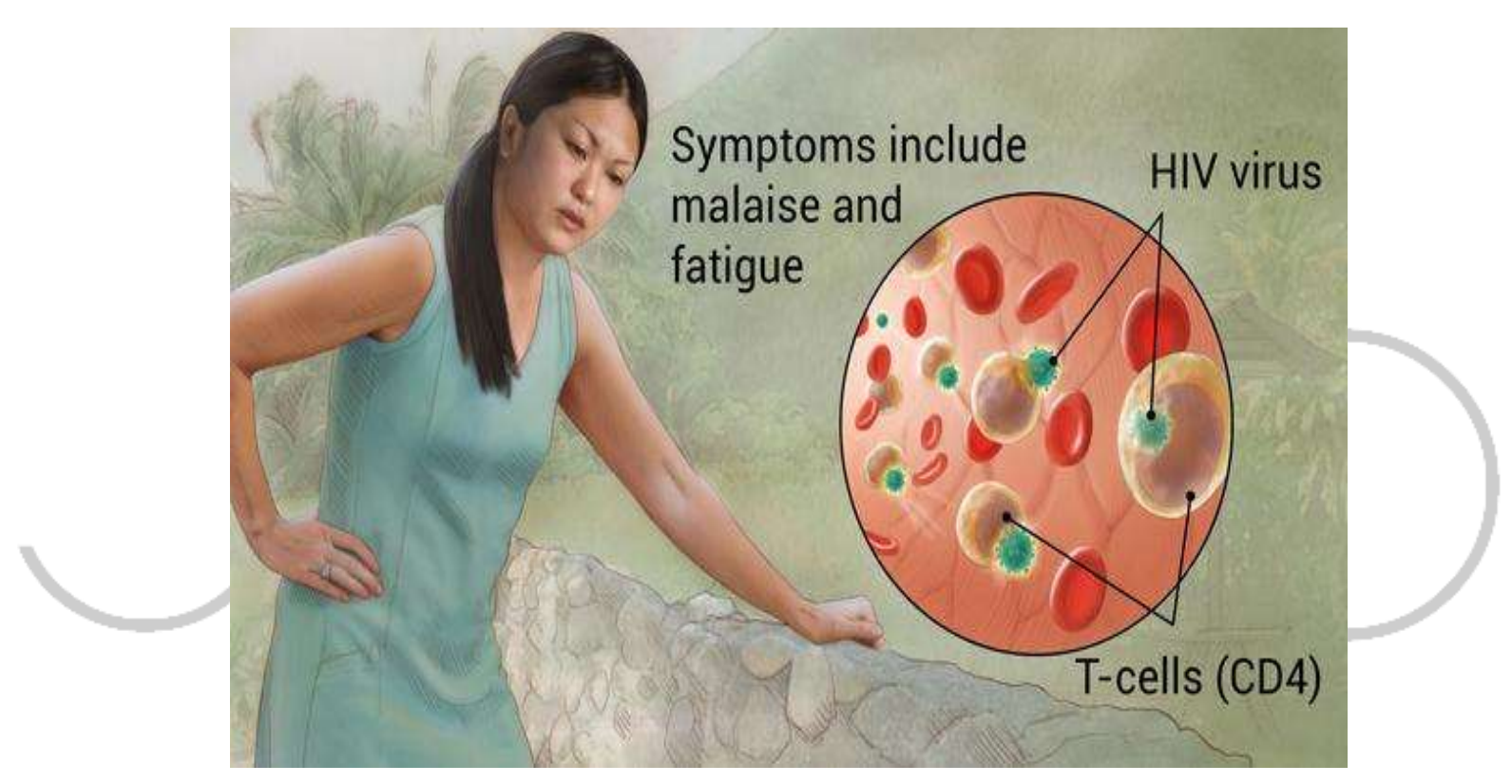

\section{HIV/AIDS in Africa}

HIV/AIDS as a public health threat of concern which lead to death in diferent parts of Africa. Even though the region has the population of around $15.2 \%$ of the sphere's population, more than $2 / 3$ of the total infected worldwide - some 35 million people - come from Africa, out of which fifteen million have already died. SubSaharan Africa alone was projected to be $69 \%$ of all people living with HIV and
$70 \%$ of all AIDS mortality in the year 2011.As of the year 2011, HIV infected almost $10 \%$ of the population in the following countries: Botswana, Malawi, Lesotho, Mozambique, , South Africa, Namibia, Eswatini, Zimbabwe and Zambia In response, some ingenuities have been launched in various parts of the African continent to educate the public on HIV/AIDS. The report of 2013 given by the Joint United Nations Programme on HIV/AIDS (UNAIDS), indicates that, HIV positive people in 
Africa receiving antiretroviral drugs in the year 2012 was more than seven times compared to the number that received treatment in 2005, "with nearly 1 million added in the last year alone". The cases of AIDS-related mortality in Sub-Saharan Africa in 2011 was 33 percent less than the number in 2005. The number of new cases of HIV infections in Sub-Saharan Africa in the year 2011 was $25 \%$ which is lowr than that in 2001. (The African Commission 2017)

\section{HIV/ AIDS in Nigeria}

Nigeria as a country is the second largest HIV epidemic in the world. (NACA2017). Though the prevalence of HIV in adults is less than (1.5\%) than when compared with other countries within sub-Saharan
African like South Africa (20.4\%), with Zambia (11.3\%), the size of Nigeria's population estimated of about1.9 million people were living with HIV in 2018.

Nonetheless, UNAIDS approximations that around 2/3 of new HIV cases in West and Central Africa in 2017 was found in Nigeria.. Six states in Nigeria accounts for 41 percent of people with HIV infection, which include:, Akwa lbom, Benue, Kaduna, Kano, Lagos and Oyo. The prevalence of HIV is higher in southern part of Nigeria (known as the South-South Zone which accounts for $5.5 \%$. But, it is lowest in the southeast zone, with prevalence rate of $1.8 \%$. There are higher rates of HIV in rural areas $(4 \%)$ than in urban ones (3\%). (NACA 2017)

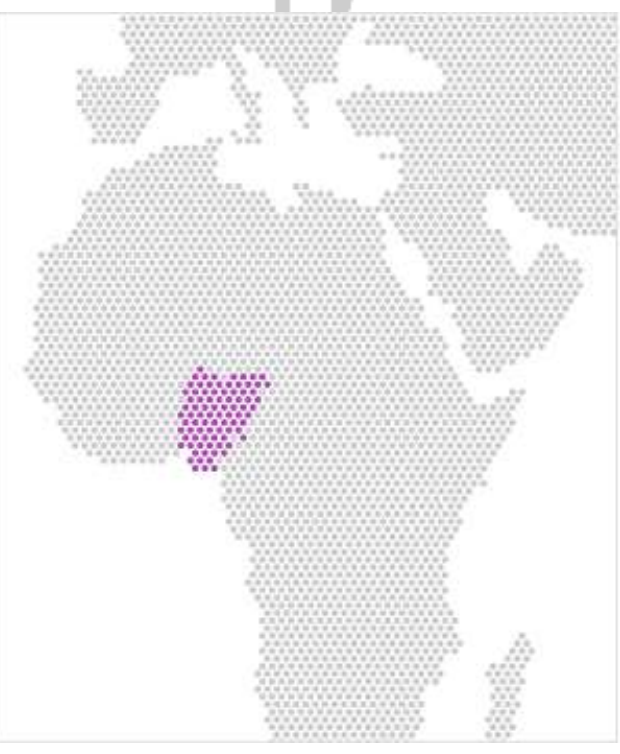

Nigeria (2018)

$1.9 \mathrm{~m}$ people living with HIV

$1.5 \%$ adult HIV prevalence (ages $15-49$ )

130,000 new HIV infections

53,000 AIDS-related deaths

$55 \%$ adults on antiretroviral treatment*

$35 \%$ children on antiretroviral treatment*

*All adults/children living with HIV

Source: UNAIDS Data 2019 


\section{NIGERIA Progress towards 909090 targets (all ages)}

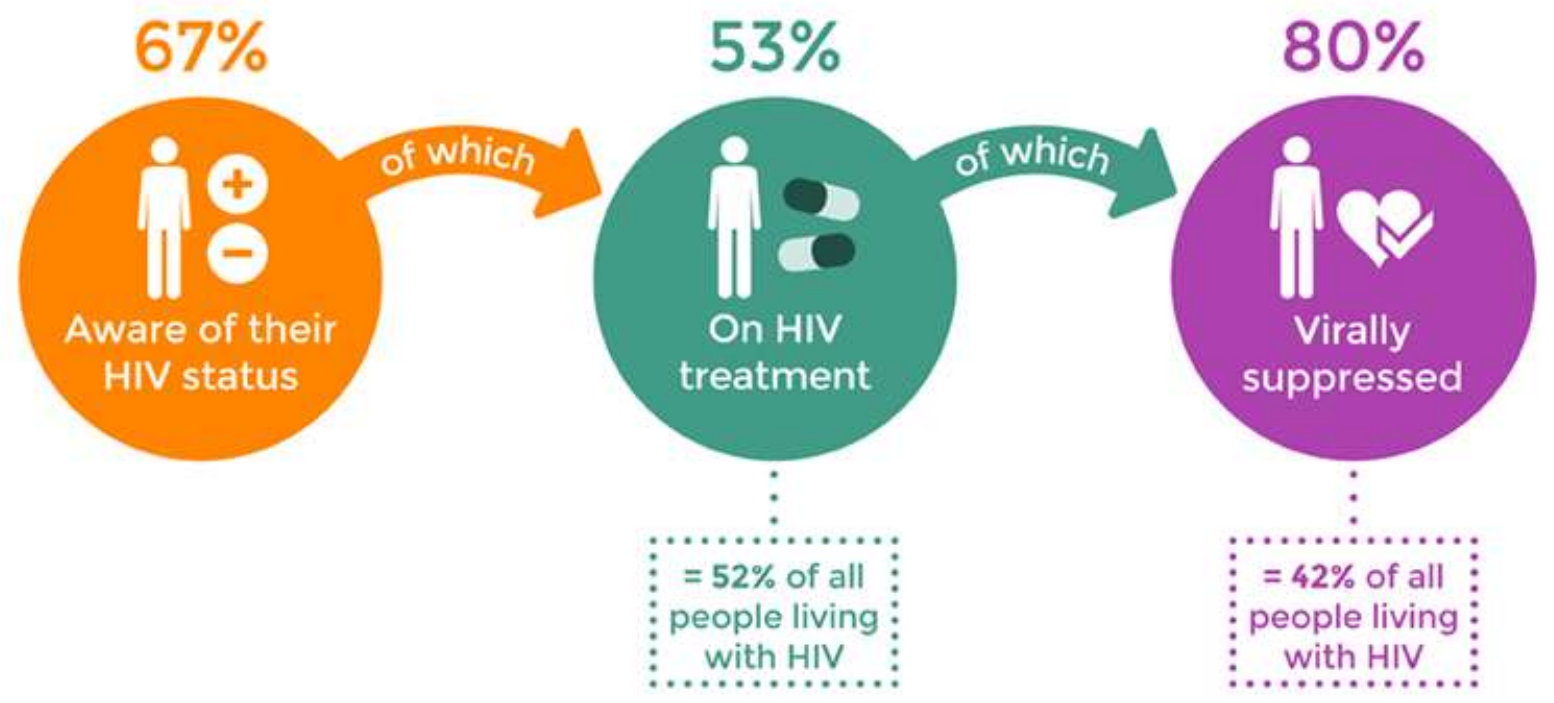

Source: UNAIDS Data 2019

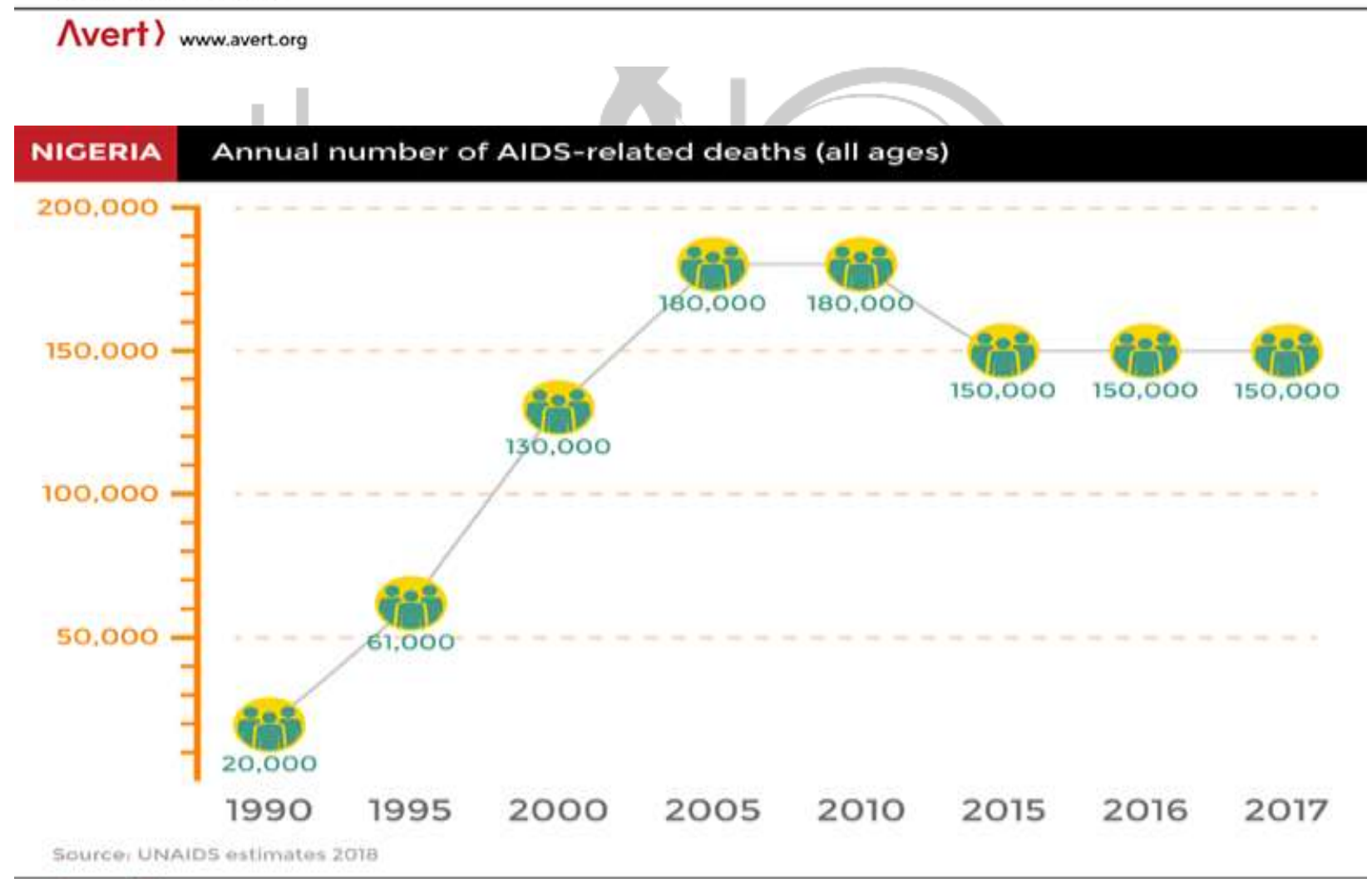

Avert) www.avert.org 
Groups that mostly affected with HIV within Nigeria

Nigeria has a mixed epidemic, meaning that while HIV prevalence among the general population is high, certain groups still carry a far more significant HIV burden compared to the rest of the community. Sex workers, Gays and people who used drugs by injection make up only $3.4 \%$ of the population, yet account for around $32 \%$ of new HIV infections.

\section{Men who have sex with men (MSM)}

Men who have sex with men are the only group in Nigeria, where HIV prevalence is still rising. In 2017, the prevalence in this category is morethan $23 \%$, the prevalence group in - sex workers - with $14.4 \%$.

A gay man living in Nigeria however, there is an improvement in HIV prevention within gays. . In 2010 , only $18 \%$ of Gays reached with HIV prevention programming, 82 percent of Gays used a condom, and $97 \%$ had tested for HIV in the previous 12 months. Stigma such as this poses a significant barricade to HIV prevention, according to the research that shown that the prevalence of HIV among men who have sex with men is directly correlated to their experiences of sexual stigma. (Schwartz et al. 2015).

Sex workers. UNAIDS (2019)

People who inject drugs (PWID) UNAIDS (2017)

Young people (Schaefer et al., 2017)
Children and orphans. PEPFAR (2017)

\section{Women in Nigeria}

In Nigeria, it is projected that 58 percent of the people living with HIV are women which placed them at higher risk of HIV. Girls Not Brides (2015)

\section{CHALLENGES ASSOCIATED WITH HIV/AIDS WITHIN THE NIGERIAN POPULACE}

Cultural barriers as a Facotr is a key to the challenges associated with HIV/AIDS in Nigeria. Girls Not Brides (2015)

\section{Legal barriers}

In thye year 2015, the Nigerian Government signed a new antidiscrimination bill into law that protected the rights of people who are living with HIV, protecting HIV-positive employees from unfair dismissal and from mandatory HIV testing. For example, one of the bill state that same-sex relations in Nigeria can be punished with 14 years of detention. However, this law is not only restricted access to HIV hindrance programme for this community but leading to national stigma and discrimination against people based on their sexual orientation. Harm Reduction International (2016)

Funding this is one of the major sector and interventions that help in addressing the HIV/AIDS in Nigeria. Harm Reduction International (2016)

HIV testing and counseling (HTC) in Nigeria in $2016,34 \%$ of adults living with 
HIV were aware of their status. There is also a mutual belief that HTC centers are where HIV-positive people go to access care, rather than them being testing centers for those who do not know their status. UNAIDS (2019)

\section{WAY FORWARD}

HIV prevention programs in Nigeria Nigeria accounted for $59 \%$ of all new HIV infections in West and Central Africa in 2016. They identify strengthening community structures as being the main way to achieve this.

Pre-exposure prophylaxis (PrEP) the report issued by new national guidelines for HIV prevention and care, shows that future expansion $₫$ of PrEP including serodiscordant couples, people who inject drugs, and commercial sex workers as well as those individuals that engage in anal sex either in long period or on regular time interval (NBS, UNICEF 2017)

\section{HIV education and family life (LLHE)} lessons are part of the Nigerian school curriculum. It was required to teach some broad list of topics concerning HIV, so as to educate everyone in the society and to avoid stigma and domestic violence due to it.

\section{Prevention of mother-to-child transmission (PMTCT)}

Morethan $1 / 4 \quad(26.9 \%)$ of all cases of mother-to-child transmission (MTCT) of HIV in the world was found in Nigeria. In 2016 , just 32 percent of women with pregnancy living with HIV received antiretroviral treatment to prevent mother-to-child transmission, and only $34.7 \%$ were tested for HIV as part of their antenatal care. As a result, the rate of mother-to-child transmission has remained high, at an estimated $22 \%$ in 2016. As such, I was reducing mother-to-child transmission remains a significant target area.

\section{Antiretroviral treatment availability (ART)}

in Nigeria. in antiretroviral therapy between 2016 and March 2017. However, weaknesses in the health system exist and create a barrier to many people accessing or staying on treatment. Even when ART can be located, drug supplies are known to run out and cause stockouts. (PEPFAR 2019)

The role of Civil society in Nigeria. A research into the part of civil society in the HIV response in Nigeria revealed that while civil society organizations (CSOs) play a crucial role in service delivery and HIV education, they rarely are allowed to directly impact on policy or play a central role in democratic processes. Although $30 \%$ of the organizations which include in the study identified advocacy as being a key area of their work, many faced difficulty in getting funding for the more administrative areas of their work. Few influenced their local village and community. The African Commission identified this as being a pivotal action to protect further and promote the human rights of critical groups. One of the activities of this proposed group would be the monitoring of the anti-HIV discrimination and stigma bill. (Schwartz et al., 2015)

\section{HIV co-infected with TB among Nigerians,} Nigeria is the 4th largest tuberculosis (TB) epidemic in the globally. It was estimated 
that $4 \%$ of global TB cases occur in Nigeria. The TB cases in Nigeria is thoroughly linked to HIV infection. Ten countries including Nigeria that together are covering the $80 \%$ of people living with HIV and TB co-infection. Low antiretroviral treatment coverage (30\%) contributes to the high rates of HIV-associated TB in the country, as being on antiretroviral treatment dramatically reduces a person living with HIV's risk of TB. (WHO TB Report 2017)

\section{Conclusion and recommendation}

Providing antiretroviral drugs for all people living with HIV will reduces the chance of onward HIV spread to others. Also commitment, funding, as well resources both human and materials are required as part of the intervention and preventive measures. Incooperating members of society, particularly the most vulnerable to HIV, is one of the key to be considered in HIV reaction.

As a final point, promising HIV testing between the Nigerians to ensure everyone knows their HIV status and to be aware with strategic plan is another key in tackling it.

\section{REFERENCES}

\section{Babayemi O Olakunde, Daniel A} Adeyinka, Sabastine S Wakdok, Tolulope T Oladele, Chamberline E Ozigbu (2018) 'Quantification of the effect of terrorism on the HIV response in Nigeria'. The Lancet, Vol 391, Issue 10127, pg 1257-1258

\section{NACA (2017) 'National Strategic} Framework on HIV and AIDS: 2017 -2021'
Nigeria Federal Ministry of Health (2010) 'HIV Integrated Biological and Behavioural Surveillance Survey (IBBSS)'

National Bureau of Statistics (NBS) and United Nations Children's Fund (UNICEF) (2017) Multiple Indicator Cluster Survey 2016-17, Survey Findings Report

PEPFAR 'Large National Survey Shows Smaller HIV Epidemic in Nigeria Than Once Thought and Highlights Key Gaps Toward Reaching HIV Epidemic Control' April 2019

Reuters (July 2017) "Mass arrest of 40 gay men in Nigeria may harm HIV fight: activist' $(30 / 04 / 2018)$

The African Commission (2017)'HIV, the law and human rights'

Schwartz, S. R., Nowak, R. G., Orazulike, I., Keshinro, B., Ake, J., Kennedy, S., andTRUST Study Group. (2015). 'The immediate effect of the Same-Sex Marriage Prohibition Act on stigma, discrimination, and engagement on HIV prevention and treatment services in men who have sex with men in Nigeria: analysis of prospective data from the TRUST cohort.' The Lancet HIV, 2(7), e299e306.

UNAIDS 'AIDSinfo' October 2018World Health Organisation (2017) 'Global Tuberculosis Report'UNAIDS (2019) 'Communities at the center: Global AIDS Update 2019', p.188 
Schaefer R., Gregson S., Eaton JW., UNAIDS (2017) 'Ending AIDS: Progress Mugurungi O., Rhead R., Takaruza A., towards the 90-90-90 targets'

Maswera R., Nyamukapa C. (2017) 'Agedisparate relationships and HIV incidence in adolescent girls and young women: evidence from Africa
Girls Not Brides (2015)_Ending child marriage in Africa: A brief by Girls Not Brides 